\title{
Combined saphenous and sciatic catheters for analgesia after major ankle surgery: a double-blinded randomized controlled trial
}

\section{Combinaison de cathéters saphène et sciatique pour l'analgésie après une chirurgie majeure de la cheville: une étude randomisée contrôlée à double insu}

\author{
Anne K. Fisker, MD • Bo N. Iversen, MD • Steffen Christensen, MD, PhD • \\ Frank Linde, MD • Kristian K. Nielsen, MD • Jens Børglum, MD, PhD • \\ Thomas F. Bendtsen, MD, PhD
}

Received: 12 September 2014/Accepted: 1 April 2015/Published online: 8 April 2015

(C) Canadian Anesthesiologists' Society 2015

\begin{abstract}
Purpose Continuous sciatic nerve block is used for pain management following major ankle surgery. Pain from the saphenous nerve territory often persists. We conducted a double-blinded randomized placebo-controlled trial to evaluate the effect of a supplementary saphenous catheter in the proximal thigh combined with a popliteal sciatic
\end{abstract}

\footnotetext{
Author contributions Anne K. Fisker was the primary investigator and Thomas F. Bendtsen is the corresponding author and sponsor. Anne K. Fisker and Thomas F. Bendtsen drafted the article. Anne K. Fisker, Frank Linde, Kristian K. Nielsen, and Thomas F. Bendtsen contributed to study conception. Anne K. Fisker, Steffen Christensen, and Thomas F. Bendtsen contributed to the study design. Anne K. Fisker contributed to data acquisition and data analysis. Frank Linde and Kristian K. Nielsen contributed to data acquisition in the orthopedic outpatient clinic. Anne K. Fisker, Bo N. Iversen, Steffen Christensen, Jens Børglum, and Thomas F. Bendtsen contributed to data interpretation. Bo N. Iversen and Thomas F. Bendtsen took part in the data acquisition by being the two regional block anesthesiologists. Bo N. Iversen, Steffen Christensen, Frank Linde, Kristian K. Nielsen, and Jens Borglum contributed to revising the article critically. Steffen Christensen and Thomas F. Bendtsen contributed to the statistical analysis.
}

A. K. Fisker, MD · B. N. Iversen, MD .

S. Christensen, MD, PhD - T. F. Bendtsen, MD, PhD ( $ه)$

Department of Anesthesia, Aarhus University Hospital,

Norrebrogade 44, 8000 Aarhus C, Denmark

e-mail: tfb@dadlnet.dk

F. Linde, MD · K. K. Nielsen, MD

Department of Orthopedic Surgery, Aarhus University Hospital,

Aarhus C, Denmark

J. Børglum, MD, $\mathrm{PhD}$

Department of Anesthesia, Roskilde Hospital, University of

Copenhagen, Roskilde, Denmark catheter and single-shot saphenous nerve block after major ankle surgery.

Methods Fifty patients received both sciatic and saphenous continuous catheters inserted along the short axis of the nerves with ultrasound-guidance. All patients had an initial sciatic nerve block followed by a continuous sciatic catheter infusion and an initial saphenous nerve block with ropivacaine. Participants were then randomized to infusion of either ropivacaine or isotonic saline in the saphenous catheter for $48 \mathrm{hr}$ postoperatively. The primary outcome was total intravenous morphine consumption during the first $48 \mathrm{hr}$ postoperatively. Secondary outcomes were clinical analgesia, saphenous analgesia, territory of worst pain, and patient satisfaction.

Results Forty-four patients were included in the analysis. The mean (SD) 48-hr morphine consumption was 24.7 (21.6) $\mathrm{mg}$ in the intervention group and 27.8 (20.1) $\mathrm{mg}$ in the placebo group $(P=0.63)$. The mean difference in 48-hr morphine consumption was $3.0 \mathrm{mg}$ (95\% confidence interval, -9.7 to 15.7). There were no differences regarding the secondary outcomes.

Conclusion $A$ saphenous catheter with a low-dose continuous infusion of ropivacaine, as an adjunct to a sciatic catheter, had no effect on the postoperative analgesia after major ankle surgery when both catheters were inserted along the short axis of the nerves. This trial was registered at ClinicalTrials.gov (NCT01445210).

\section{Résumé}

Objectif Après une chirurgie majeure de la cheville, le bloc continu du nerf sciatique est utilisé pour soulager la douleur, mais bien souvent, des douleurs issues $d u$ 
territoire du nerf saphène persistent. Nous avons réalisé une étude randomisée à double insu et contrôlée par placebo afin d'évaluer l'effet d'un cathéter saphène supplémentaire dans la cuisse proximale combiné à un cathéter sciatique poplité et à un bloc du nerf saphène en injection unique après une chirurgie majeure de la cheville.

Méthode Deux cathéters continus ont été installés sous échoguidage aux nerfs sciatique et saphène le long des axes nerveux courts chez cinquante patients. Tous les patients ont reçu un bloc initial du nerf sciatique suivi d'une perfusion continue via le cathéter sciatique et un bloc initial du nerf saphène avec de la ropivacaïne. On a ensuite réparti les participants en deux groupes, l'un recevant une perfusion de ropivacaïne et l'autre une solution saline isotonique dans le cathéter saphène pendant 48 h après l'opération. Le critère d'évaluation principal était la consommation totale de morphine intraveineuse au cours des $48 \mathrm{~h}$ suivant l'opération. Les critères d'évaluation secondaires étaient l'analgésie clinique, l'analgésie saphène, le territoire de la douleur la plus forte, et la satisfaction du patient.

Résultats Quarante-quatre patients ont été inclus dans notre analyse. La consommation moyenne (ÉT) de morphine en 48 hétait de $24,7(21,6) \mathrm{mg}$ dans le groupe intervention et de 27,8 (20,1) mg dans le groupe placebo $(P=0,63) . \quad$ La différence moyenne en matière de consommation de morphine sur $48 \mathrm{~h}$ était de 3,0 $\mathrm{mg}$ (intervalle de confiance $95 \%,-9,7$ à 15,7). Aucune différence n'a été observée au niveau des critères d'évaluation secondaires.

Conclusion Un cathéter saphène avec une perfusion continue de ropivacaïne à faible dose, en tant qu'ajout à un cathéter sciatique, n'a pas eu d'effet sur l'analgésie postopératoire après une chirurgie majeure de la cheville lorsque les deux cathéters étaient placés le long de l'axe court des nerfs. Cette étude est enregistrée au ClinicalTrials.gov (NCT01445210).

Major hindfoot and ankle surgery is associated with severe pain for the first 48-72 $\mathrm{hr}$ following surgery. ${ }^{1,2}$ Traditional opioid-based postoperative pain management provides inadequate pain relief and is associated with unwanted opioid-related side effects. Both the sciatic and saphenous nerves supply sensory innervation of the foot and ankle joint, including innervation of the capsule of the ankle and the talocalcaneonavicular joint. ${ }^{3,4}$ Despite effective continuous sciatic nerve block, many patients report moderate to severe pain from the saphenous nerve territory during the first two postoperative days if the surgery has involved the anteromedial side of the ankle.,
An ultrasound-guided single-injection saphenous nerve block in the adductor canal provides effective sensory block of the anteromedial aspect of the ankle lasting $12 \mathrm{hr}^{7}$ A continuous femoral nerve block can control pain from the saphenous territory, ${ }^{8}$ but it leads to significant motor weakness of the quadriceps femoris muscle. ${ }^{9}$ A supplemental continuous selective blockade of the sensory saphenous nerve might be suitable.

Trials using an ultrasound-guided subsartorial approach to insert a saphenous catheter in the upper third of the thigh for analgesia following knee arthroplasty have employed an in-plane technique and a short-axis view of the target nerve. ${ }^{9-11}$ To date, trials are lacking on the effect of a postoperative continuous saphenous nerve block after major ankle surgery.

The purpose of our study was to determine if continuous saphenous catheter analgesia combined with continuous sciatic catheter analgesia and single-shot saphenous block would reduce 48-hr morphine consumption in patients undergoing major ankle and hindfoot surgery. Secondary objectives included a comparison of the proportion of patients reporting a numeric rating scale (NRS) pain score $\leq 3$ in the whole foot and ankle region $v s$ in the saphenous territory alone - both without opioid supplementation; sensory thermanalgesia in the territory of the sciatic nerve; the region of worst pain; and patient satisfaction.

\section{Methods}

The study was approved by the Central Denmark Region Committee on Biomedical Research Ethics (M-20110184) in September 2011, and written informed consent was obtained from all patients. The study was conducted in accordance with good clinical practice guidelines.

Patients were recruited from October 2011 to October 2012 at Aarhus University Hospital, Denmark. Aarhus University hospital is one of the largest Northern European university hospitals with more than 10,000 employees, 1,150 beds, 198,500 inpatients, and 793,000 outpatients annually. Each year, the foot and ankle surgery section of the Department of Orthopedic Surgery performs approximately 120 major elective hindfoot and ankle surgeries associated with pain in the distribution of the saphenous nerve.

Eligibility criteria for the study were patients older than $18 \mathrm{yr}$, American Society of Anesthesiologists' (ASA) physical status I-III, and scheduled for total ankle alloplasty, subtalar arthrodesis, or open ankle arthrodesis. Exclusion criteria included patients with coagulation defects, local infection at the catheter insertion site, systemic infection, preoperative use of strong opioids 
(morphine and synthetic opioids), neuropathy of the sciatic or femoral nerves, impaired sensation of the lower extremities, diabetic neuropathy, Charcot-Marie-Tooth disease, significant peripheral vascular disease, allergy to local anesthetics, inability to comprehend the NRS, communicative disability, dementia, body mass index $>35 \mathrm{~kg} \cdot \mathrm{m}^{-2}$, and need for bilateral surgery. The main investigator (A.K.F.) enrolled the patients.

On the day of surgery, a peripheral intravenous access was established with an infusion of isotonic saline and antibiotics in all patients along with application of standard monitoring (pulse oximetry, 3-lead electrocardiogram, and noninvasive blood pressure). Fentanyl 50-100 $\mu \mathrm{g} i v$ was used for analgesia as required during placement of the catheters. Two staff anesthesiologists with extensive expertise in ultrasound-guided regional anesthesia (T.F.B. and B.N.I.) performed all nerve blocks and catheter insertions preoperatively.

Saphenous nerve catheters were placed with the participants in a supine position, the limb rotated laterally at the hip, and the knee slightly flexed. The $15-6 \mathrm{MHz}$ ultrasound transducer (HFL50; SonoSite, Bothell, WA, USA) was placed on the proximal thigh on top of the sartorius muscle. The needle insertion point was at the level of the femoral triangle at the midpoint of the proximal third of the distance between the base of the patella and the lower border of the greater trochanter. This needle insertion point is approximately identical to the midpoint between the anterior superior iliac spine and the base of the patella. ${ }^{12}$ The area was swabbed with $2 \%$ chlorhexidine in $70 \%$ isopropyl alcohol and draped with a sterile fenestrated sheet. The transducer was draped with a sterile cover and placed perpendicular to the skin medially on the thigh to obtain a short-axis view of the femoral vessels and the sartorius muscle. At this level, the saphenous nerve is always located just anterior to the artery using the anatomical position. ${ }^{13,14}$ This location is termed "lateral" by many regional anesthesiologists who label orientation using the ultrasound probe as reference. ${ }^{15}$

After local skin infiltration with $1 \%$ lidocaine $2 \mathrm{~mL}$, a Contiplex $^{\circledR} \mathrm{S}$ Ultra needle $(18 \mathrm{G} \times 4$ in) (B Braun, Melsungen AG, Germany) was advanced in plane into the anatomical space delimited by the sartorius muscle, the medial vastus muscle, and the femoral artery until the needle closely approached the nerve, as judged by visualization of the needle tip. Meticulous care was taken to avoid piercing the branches of the femoral nerve to the medial vastus muscle, which are ramifying in the fascial plane between the sartorius and medial vastus muscles or inside the medial vastus muscle at this level. The appropriate position of the needle tip was verified with perineural spread of $1 \mathrm{~mL}$ of injected saline. Ten millilitres of $0.375 \%$ ropivacaine were injected with intermittent aspiration. A Contiplex S Ultra catheter $(0.85 \mathrm{~mm} \times 1,000 \mathrm{~mm}) \quad(\mathrm{B}$ Braun, Melsungen AG, Germany) was then inserted along the short axis of the nerve via the needle. The correct position of the catheter tip was verified by injection and successful perineural spread of $1 \mathrm{~mL}$ of saline via the catheter. In case of misplaced spread, the position of the catheter tip was adjusted until the perineural spread of saline was successful. The saphenous nerve block was considered successful if thermanalgesia was manifest in the area proximal to the medial malleolus ten minutes after injection.

Placement of the popliteal sciatic nerve catheter was performed with the lateral approach and with the participants in the lateral decubitus position. The neurovascular structures in the popliteal fossa were imaged in the short-axis view with ultrasound. The sciatic nerve bifurcation was located, and the needle was advanced in plane from the lateral side of the thigh just anterior to the tendon of the long head of the biceps femoris muscle and with the short-axis view of the target nerve aiming just proximal to the sciatic bifurcation. The popliteal sciatic nerve block was then initiated with injection of $0.75 \%$ ropivacaine $20 \mathrm{~mL}$. Placement of the sciatic catheter along the short axis was performed and controlled in a similar manner to that of the saphenous nerve catheter.

All catheters were fixed to the skin with $0.5 \mathrm{~g}$ of LiquiBand $^{\circledR}$ Standard tissue adhesive (MedLogic Global Limited, Plymouth, UK) and covered by Tegaderm ${ }^{\mathrm{TM}}$ transparent dressing $(10 \mathrm{~cm} \times 12 \mathrm{~cm})(3 \mathrm{M}$ Health Care, Neuss, Germany).

All participants received standardized general anesthesia in addition to nerve blockade. The administration of propofol and remifentanil was titrated to acceptance of the laryngeal mask airway device and the thigh tourniquet. The tourniquet was applied around the thigh distal to the saphenous catheter insertion site and was inflated to 250-300 mmHg. The propofol infusion was stopped at the time of deflation of the tourniquet, and the remifentanil infusion was stopped at the end of surgery.

All patients were observed at the postanesthesia care unit (PACU) after surgery. Fentanyl 50-100 $\mu \mathrm{g} i v$ was administered as required to alleviate pain in the PACU.

On arrival at the postoperative ward, participants were randomly allocated to two parallel groups in a one:one allocation ratio using a computer-generated list of random numbers in sealed envelopes. The intervention group received a continuous infusion of $0.2 \%$ ropivacaine $5 \mathrm{~mL} \cdot \mathrm{hr}^{-1}$ in the saphenous catheter for $48 \mathrm{hr}$, and the placebo group received a matching continuous infusion of isotonic saline. An Easypump ${ }^{\circledR}$ C-bloc RA elastomeric pump (B. Braun, Melsungen AG, Germany) with a fixed infusion rate of $5 \mathrm{~mL} \cdot \mathrm{hr}^{-1}$ was filled with $280 \mathrm{~mL}$ of 
project medicine. Randomization was blocked in groups of ten and not stratified by surgical procedure. The research staff, project manager, and participants were blinded to study group allocation as ropivacaine and saline containers were labelled only as "project medicine". An independent person not involved in other parts of the study generated the random allocation sequence and provided the blinded "project medicine".

Forty-eight hours after surgery, the infusion was stopped. It was not possible to administer boluses in the saphenous catheter in case of breakthrough pain.

Participants in both groups received a continuous infusion of $0.2 \%$ ropivacaine $10 \mathrm{~mL} \cdot \mathrm{hr}^{-1}$ in the popliteal sciatic catheter via an electronic infusion pump. Both groups had the option of an additional bolus of ropivacaine $10 \mathrm{~mL}$ (maximum four times per $24 \mathrm{hr}$ ) in the popliteal sciatic nerve catheter in case of breakthrough pain.

Acetaminophen was administered to all patients, one gram orally four times per day, and intravenous morphine was used as rescue medication. According to the surgical prescriptions, patients were not allowed to mobilize during the first 48 postoperative hours.

The following data were recorded for each patient: age, sex, weight, height, ASA score, type of surgery, preoperative pain at rest (NRS), preoperative consumption of mild opioids, and fentanyl consumption in the PACU.

The primary outcome was consumption of intravenous morphine equivalents during the first $48 \mathrm{hr}$ following surgery. The postoperative time began when the patient arrived at the PACU after surgery. Morphine was administered intravenously in case of breakthrough pain in the saphenous territory on the anteromedial side of the ankle or if the bolus of ropivacaine in the popliteal sciatic catheter did not alleviate the pain effectively after $15 \mathrm{~min}$. When the NRS pain score was $>3$, morphine $10 \mathrm{mg} \cdot \mathrm{mL}^{-1}$ $0.05-0.1 \mathrm{mg} \cdot \mathrm{kg}^{-1} i v$ was administered. If morphine was not tolerated, equipotent doses of a synthetic opioid were used. If morphine was administered orally, the dose was converted to an equivalent intravenous dosage. ${ }^{16}$ The project manager recorded the data on opioid consumption from the electronic patient registration system, including all data on drug dispensing in hospital at the completion of the scheduled study period. The project manager was blinded to group allocation at the time of data sampling.

\section{Secondary outcomes}

Clinical analgesia of the foot and ankle was defined as $\mathrm{NRS} \leq 3$ without opioid supplementation at all data sampling time points. The data sampling time points were: at the arrival at and departure from the PACU and at six, 12, 24, and $48 \mathrm{hr}$ after the initial nerve blocks. Clinical analgesia of the foot and ankle was scored without subgroup division. Analgesia was estimated using an NRS score from $0=$ "no pain" to $10=$ "worst possible pain".

It was not possible to test the sensory blockade of the cutaneous territory of the saphenous nerve at the anteromedial side of the ankle due to postoperative application of a circumferential plaster extending from just proximal to the toes to just below the knee. Therefore, successful analgesia in the saphenous nerve territory was defined as NRS $\leq 3$ at all data sampling time points (same as above) without opioids. Saphenous analgesia was only estimated in the subgroup of patients with complete sensory thermanalgesia (no cold sensation) of the tibial and common peroneal nerves at all data sampling time points.

Successful sensory thermanalgesia of the tibial and common peroneal branches of the sciatic nerve was defined as complete or partial sensory thermanalgesia at all data sampling time points. The data sampling time points were the same as above. Sensory thermanalgesia was evaluated by testing cold sensation using ethanol swabs applied on the dorsal side (common peroneal nerve) and the plantar side (tibial nerve) of the toes compared with the contralateral toes. Cold sensation was scored as follows: $0=$ no cold sensation (complete sensory block); $1=$ reduced cold sensation (partial sensory block); and $2=$ normal cold sensation (no sensory block). The sensory assessment was performed while the catheter infusions were running.

The territory of worst postoperative pain could be the sensory region of the saphenous nerve (anteromedial side of the ankle joint) or the sciatic nerve (all other localization in the ankle and foot). The data sampling time points were the same as above.

The project manager evaluated patient satisfaction with regional anesthesia by questioning the patient after the first 48 postoperative hours. Patient satisfaction with the postoperative pain treatment was quantified as NRS scores from $0=$ "completely dissatisfied" to $10=$ "completely satisfied".

At a standardized single-blinded telephone interview six months after surgery, the project manager asked the patients about the presence at any time of complications possibly related to peripheral nerve blocks, e.g., paresthesia, hematomas, and local infections. The patients were blinded to group allocation.

The sample size was calculated to show a significant difference in morphine consumption during the first 48 postoperative hours, assuming that the mean standard deviation (SD) consumption would be 30 (20) $\mathrm{mg}$ in the placebo group and 10 (10) $\mathrm{mg}$ in the intervention group, 
which would correspond with a $66 \%$ reduction in morphine consumption. The sample size needed to detect this difference with $80 \%$ power and a two-tailed alpha error of 0.05 was 16 patients in each group. We sampled 25 patients in each group to allow for dropouts.

Statistical analyses were conducted in STATA 11.1 (STATA, College Station, TX, USA) and graphs were made in STATA 11.1. Continuous variables (consumption of morphine) were tested for Gaussian distribution (Kolmogorov-Smirnov test), and normal continuous distributions were analysed with Student's $t$ test. Data were presented as mean with standard deviation (SD), and the mean difference between groups was presented with 95\% confidence interval. Continuous data with non-normal distribution as well as ordinal variables (NRS) were compared using the Wilcoxon-Mann-Whitney test. Data were presented as median and interquartile range. Categorical variables (proportions with clinical analgesia, saphenous analgesia, sciatic analgesia, and territory of worst pain) were analysed with Chi square or Fisher's exact test as appropriate. All reported $P$ values are two sided.

\section{Results}

Fifty participants were included in the study, and six were excluded after allocation because of protocol violation (Fig. 1). The protocol violations were non-delivery of ropivacaine by the elastomeric pumps, non-protocol supplemental ropivacaine bolus injection via the saphenous catheter, or incorrect sciatic catheter infusion rates. One diabetic patient with manifest neuropathy was incorrectly included.
Participant demographics, surgical procedures, and fentanyl consumption in the PACU were similar in both study groups (Table 1).

All participants had thermanalgesia proximal to the medial malleolus ten minutes after the initial saphenous nerve block, indicating a successful block. All saphenous catheters were successfully located in the proximal thigh as verified using sonography to visualize perineural spread by an injection through the catheter. Likewise, all sciatic nerve catheters were successfully located at the popliteal fossa as verified by sonography to visualize perineural spread. None of the catheters were removed before the end of the 48-hr follow-up period.

The mean (SD) total morphine consumption during the first 48 postoperative hours was 24.7 (21.6) $\mathrm{mg}$ in the intervention group and 27.8 (20.1) $\mathrm{mg}$ in the placebo group $(P=0.63)$ (Table 2 and Fig. 2). The mean difference in total morphine consumption was $3.0 \mathrm{mg}$; $95 \% \mathrm{CI},-9.7$ to 15.7.

Eight of 20 (40\%) participants in the intervention group achieved NRS $\leq 3$ without opioid analgesia compared with seven of $24(29 \%)$ in the control group $(P=0.45)$.

Only eight participants reported complete sensory thermanalgesia (no cold sensation) of both sciatic nerve territories at all assessment time points; consequently, analysis of saphenous analgesia could not be performed per protocol. Seven of 20 participants $(35 \%)$ in the intervention group attributed the worst pain to the saphenous territory compared with 13 of 24 participants $(54 \%)$ in the control group $(P=0.17)$. Participant satisfaction with the pain treatment during the first $48 \mathrm{hr}$ postoperatively was similar in the two study groups (intervention median $10 \mathrm{vs}$ placebo 9; $P=0.15$ ) (Table 2).
Fig. 1 Patient flow diagram. $\mathrm{CSaNI}=$ continuous saphenous nerve infusion, $\mathrm{CScNI}=$ continuous sciatic nerve infusion

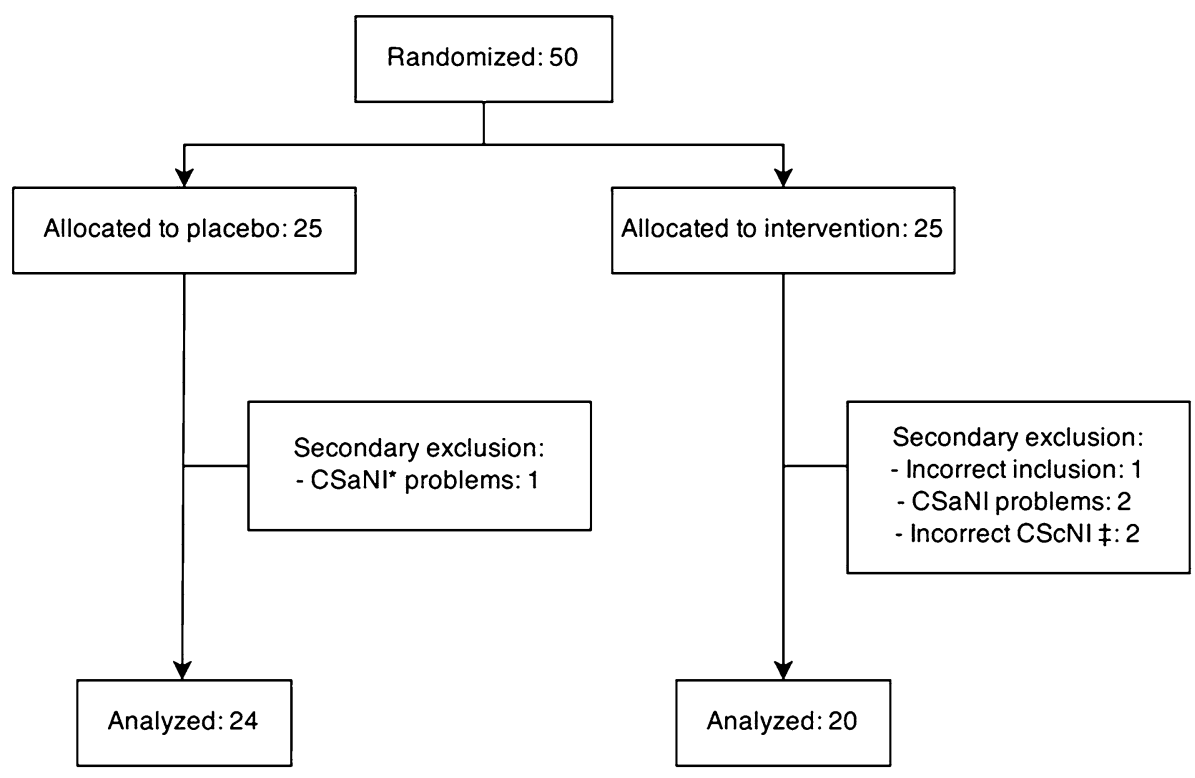


Table 1 Patient demographic data

\begin{tabular}{lll}
\hline & $\begin{array}{l}\text { Intervention } \\
n=20\end{array}$ & $\begin{array}{l}\text { Placebo } \\
n=24\end{array}$ \\
\hline Age $(\mathrm{yr})$ & $61.5(13.0)$ & $60.3(10.2)$ \\
Sex $(\mathrm{male})$ & $12(60 \%)$ & $14(58 \%)$ \\
Weight $(\mathrm{kg})$ & $76.2(14.1)$ & $83.0(14.5)$ \\
Height $(\mathrm{m})$ & $1.72(0.09)$ & $1.73(0.09)$ \\
BMI $\left(\mathrm{kg} \cdot \mathrm{m}^{-2}\right)$ & $25.7(3.9)$ & $27.8(4.0)$ \\
ASA physical status (I-III) & & \\
I & $8(40 \%)$ & $9(37 \%)$ \\
II & $11(55 \%)$ & $14(58 \%)$ \\
III & $1(5 \%)$ & $1(4 \%)$ \\
Preoperative weak opioid consumption & $4(20 \%)$ & $2(8 \%)$ \\
Surgical procedures & & \\
Total ankle replacement & $7(35 \%)$ & $14(58 \%)$ \\
Ankle arthrodesis, open & $4(20 \%)$ & $3(13 \%)$ \\
Subtalar arthrodesis & $9(45 \%)$ & $7(29 \%)$ \\
Preoperative pain at rest, NRS (0-10) & $3[0-8]$ & $4[0-7]$ \\
Fentanyl PACU, $\mu \mathrm{g}$ & $0(0)$ & $0(0)$ \\
\hline Variabs & &
\end{tabular}

Variables described as mean (SD); count (\%); and median [interquartile range]. ASA $=$ American Society of Anesthesiologists

$\mathrm{BMI}=$ body mass index; $\mathrm{NRS}=$ numeric rating scale for pain; $\mathrm{PACU}=$ postanesthesia care unit

At the six-month telephone follow-up, no participants experienced paralysis, paresthesia, or catheter-related hematoma or infection.

\section{Discussion}

In this double-blinded randomized controlled trial (RCT), we found that a continuous infusion of local anesthetics via a saphenous catheter as an adjunct to a single-injection saphenous nerve block and a popliteal sciatic catheter infusion did not reduce the 48-hr morphine consumption after major hindfoot and ankle surgery. Neither the frequency of clinical analgesia nor the proportion of patients who attributed their worst pain to the saphenous territory differed statistically between groups. We were not able to test saphenous analgesia per protocol due to the very limited number of participants with complete sensory thermanalgesia (no cold sensation) of the tibial and common peroneal nerves at all data sampling time points.

It is well established that peripheral nerve blocks effectively alleviate pain after major ankle surgery. Several studies support that a continuous sciatic nerve block after major ankle surgery reduces pain ${ }^{17-21}$ and morphine consumption. ${ }^{18,21-23}$ Other studies conclude that, despite an effective sciatic nerve block, moderate to severe postoperative pain persists from the saphenous territory. ${ }^{5,19}$
Table 2 Characteristics of nerve blocks and analgesia

\begin{tabular}{llll}
\hline & $\begin{array}{l}\text { Intervention } \\
n=20\end{array}$ & $\begin{array}{l}\text { Placebo } \\
n=24\end{array}$ & $P$ value \\
& $24.7(21.6)$ & $\begin{array}{l}27.8 \\
(20.1)\end{array}$ & 0.63 \\
$\begin{array}{l}\text { Morphine total 0-48 hr } \\
\text { postoperative (mg) }\end{array}$ & & \\
Pain, NRS (0-10) & $0(0)$ & $0[0-1]$ & \\
Arrival PACU & $0(0)$ & $0(0)$ & \\
Departure PACU & $0(0)$ & $0(0)$ & \\
6 hr & $0[0-1]$ & $0[0-1]$ & \\
12 hr & $3[0-8]$ & $4[0-9]$ & \\
24 hr & $2[0-5]$ & $1[0-4]$ & \\
48 hr & $9(45)$ & $13(54)$ & 0.11 \\
Successful sciatic analgesia $n(\%)$ & $7(29)$ & 0.45 \\
Successful clinical analgesia $n(\%)$ & $8(40)$ & $7(29)$ & 0.33 \\
Territory of worst pain $n(\%)$ & & & 0.62 \\
No pain & $8(40)$ & $7(29)$ & 0.17 \\
Saphenous & $7(35)$ & $13(54)$ & 0.43 \\
Sciatic & $2(10)$ & $1(4)$ & 0.58 \\
Saphenous and sciatic & $3(15)$ & $3(13)$ & 0.15 \\
Patient satisfaction, NRS $(0-10)$ & $10[8-10]$ & $9[7-10]$ & 0.15 \\
\hline
\end{tabular}

Values are: Morphine consumption mean (SD); pain scores and patient satisfaction median [interquartile range]; successful analgesia and territory of worst pain, count (\%)

$\mathrm{NRS}=$ numerical rating scale; PACU $=$ postanesthesia care unit; 6-48 $\mathrm{hr}$ are hours after block performance; $n=$ number

In a non-blinded RCT, Blumenthal et al. ${ }^{8}$ compared the analgesic effect of adding a femoral nerve catheter to a popliteal sciatic nerve catheter after major ankle surgery with the analgesic effect of a popliteal sciatic nerve catheter alone. Their study results showed a reduction in morphine consumption and a difference in pain during mobilization between the two groups within the first 48 postoperative hours. These results emphasize the role of the saphenous nerve in pain generation after major ankle and hindfoot surgery.

The location and approach of our saphenous nerve block was similar to that reported in recent trials employing the so-called adductor canal block (ACB) for total knee arthroplasty ${ }^{10,11,24-26}$ and minor knee surgery. ${ }^{27-29}$ Pain scores at knee flexion were reduced ${ }^{10,11,24,25}$ by the ACB; however, the effects on postoperative morphine consumption and pain at rest were inconsistent.

The study was powered to detect a $66 \%$ reduction in postoperative morphine consumption. We did not consider it clinically relevant to power the study to detect minor differences in morphine consumption between the groups, because insertion of a catheter is not cost-effective when compared with a single injection due to the expenditure of commodities for catheter insertion and longer performance time. $^{30}$ 


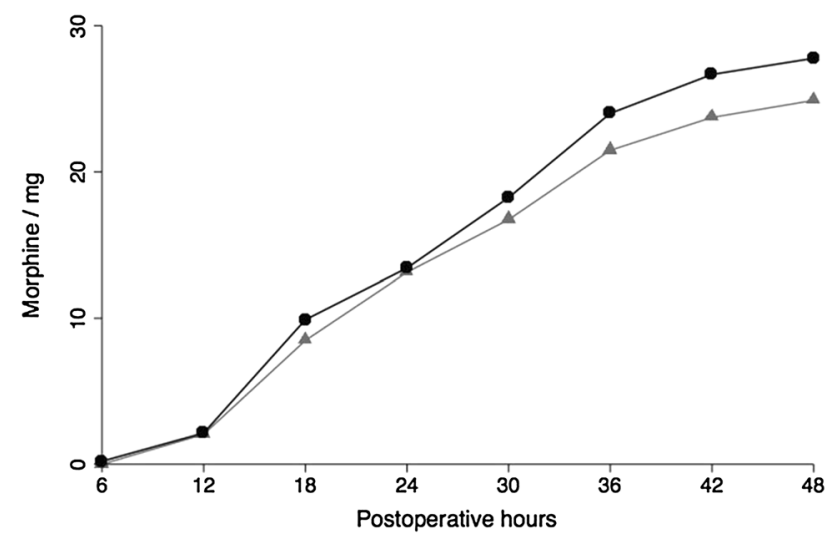

Fig. 2 Total morphine consumption from 6-48 hr postoperatively in patients receiving continuous infusion of ropivacaine (_- intervention) or saline (-placebo) via a saphenous nerve catheter placed subsartorially in the proximal thigh. Data are presented as mean. Total morphine consumption at 48 postoperative hours was not reduced in the intervention group $(P=0.63)$

Our trial has several limitations. Our primary outcome was nurse-controlled administration of morphine. Our protocol standardized the nurse-administered dosing of morphine using strict definitions on how to treat breakthrough pain. All nurses involved in the project were given thorough instructions regarding the protocol. This was possible as the patients were admitted to a small highly specialized foot and ankle stationary ward staffed with the same dedicated nurse team around the clock. In our estimation, the possible added difference in morphine consumption due to variance between nurses had limited impact on our results. Next, determination of the effectiveness of the continuous saphenous nerve block was clouded by the use of single-shot saphenous blocks in both groups. The duration of the initial saphenous nerve block with $0.375 \%$ ropivacaine $10 \mathrm{~mL}$ before breakthrough pain from the anteromedial side of the ankle joint was approximately $12-15 \mathrm{hr}$, and we did not expect postoperative pain relief beyond this point. Complaints of pain in the saphenous distribution were statistically similar in both the intervention and control groups, but sciatic analgesia was effective in only half of all study subjects, making it difficult to determine the duration and effect of the initial injections. We were unable to assess the effect of the saphenous nerve block with direct sensory testing due to the surgical dressing. Catheters inserted perpendicular to the long axis of the target nerve may be prone to secondary displacement, and a recent study showed a high frequency of secondary displacement of saphenous catheters. ${ }^{10}$ Therefore, our estimate of the effectiveness of continuous saphenous analgesia is limited and can be inferred only from the participants' complaints of pain in the saphenous nerve territory. Some may question the relatively low volume of continuous infusion $\left(5 \mathrm{~mL} \cdot \mathrm{hr}^{-1}\right)$ used in this study. Administration of intermittent boluses of local anesthetics via the catheter might be more efficient, as it can be speculated that higher injection pressure will increase the probability of complete circumferential spread around the target nerve. A catheter infusion rate of $5 \mathrm{~mL} \cdot \mathrm{hr}^{-1}$ is identical to the femoral catheter infusion rate proven to be efficient by Blumenthal et al. The saphenous nerve is much smaller and contains much less connective tissue (endoneurium, perineurium, and epineurium) than the femoral nerve. Therefore, it is unlikely that the low-dose infusion rate employed in our study would be insufficient to anesthetize the saphenous nerve.

\section{Conclusion}

The addition of a continuous saphenous nerve block to a continuous sciatic and single-injection saphenous nerve block after major ankle surgery was evaluated. No difference was found in morphine consumption, clinical analgesia, or pain localization during the first 48 postoperative hours when both catheters were inserted along the short axis of the nerve. The modest use of postoperative morphine, low pain scores, and high satisfaction of participants indicates that the combination of sciatic catheters and single-shot saphenous blocks provided effective analgesia for ankle and hindfoot surgery with little added benefit from a continuous saphenous blockade.

Acknowledgement The authors thank the staff on the Postanesthesia Care Unit and the Department of Orthopedic Surgery, Aarhus University Hospital, Aarhus, Denmark.

\section{Conflicts of interest None declared.}

Competing interests Funding was received from the Faculty of Health, Aarhus University and the Departments of Anesthesia and Orthopedic Surgery, Aarhus University Hospital, Aarhus, Denmark. Preliminary data were presented at the European Society of Regional Anaesthesia (ESRA) annual meeting in Bordeaux, France 2012.

\section{References}

1. McGrath B, Elgendy H, Chung F, Kamming D, Curti B, King S. Thirty percent of patients have moderate to severe pain $24 \mathrm{hr}$ after ambulatory surgery: a survey of 5,703 patients. Can J Anesth 2004; 51: 886-91.

2. Sevarino FB, Preble LM. A Manual for Acute Postoperative Pain Management. New York: Raven Press; 1992.

3. Mentzel M, Fleischmann W, Bauer G, Kinzl L. Ankle joint denervation. Part 1: Anatomy - the sensory innervation of the ankle joint. Foot Ankle Surg 1999; 5: 15-20. 
4. Marsland D, Dray A, Little NJ, Solan MC. The saphenous nerve in foot and ankle surgery: its variable anatomy and relevance. Foot Ankle Surg 2013; 19: 76-9.

5. Bendtsen TF, Nielsen TD, Rohde CV, Kibak $K$, Linde $F$. Ultrasound guidance improves a continuous popliteal sciatic nerve block when compared with nerve stimulation. Reg Anesth Pain Med 2011; 36: 181-4.

6. Chen J, Lesser J, Hadzic A, Resta-Flarer F. The importance of the proximal saphenous nerve block for foot and ankle surgery. Reg Anesth Pain Med 2013; 38: 372.

7. Manickam B, Perlas A, Duggan E, Brull R, Chan VW, Ramlogan $R$. Feasibility and efficacy of ultrasound-guided block of the saphenous nerve in the adductor canal. Reg Anesth Pain Med 2009; 34: 578-80.

8. Blumenthal S, Borgeat A, Neudorfer C, Bertolini R, Espinosa N, Aguirre $J$. Additional femoral catheter in combination with popliteal catheter for analgesia after major ankle surgery. $\mathrm{Br} \mathrm{J}$ Anaesth 2011; 106: 387-93.

9. Jaeger P, Zaric D, Fomsgaard JS, et al. Adductor canal block versus femoral nerve block for analgesia after total knee arthroplasty: a randomized, double-blind study. Reg Anesth Pain Med 2013; 38: 526-32.

10. Andersen HL, Gyrn J, Moller L, Christensen B, Zaric D. Continuous saphenous nerve block as supplement to single-dose local infiltration analgesia for postoperative pain management after total knee arthroplasty. Reg Anesth Pain Med 2013; 38 : 106-11.

11. Jenstrup MT, Jaeger P, Lund J, et al. Effects of adductor-canalblockade on pain and ambulation after total knee arthroplasty: a randomized study. Acta Anaesthesiol Scand 2012; 56: 357-64.

12. Bendtsen TF, Moriggl B, Chan V, Pedersen EM, Borglum J. Redefining the adductor canal block. Reg Anesth Pain Med 2014; 39: 442-3.

13. Horn JL, Pitsch T, Salinas F, Benninger B. Anatomic basis to the ultrasound-guided approach for saphenous nerve blockade. Reg Anesth Pain Med 2009; 34: 486-9.

14. Kapoor $R$, Adhikary SD, Siefring $C$, McQuillan PM. The saphenous nerve and its relationship to the nerve to the vastus medialis in and around the adductor canal: an anatomical study. Acta Anaesthesiol Scand 2012; 56: 365-7.

15. Weller RS, Henshaw DS. The use of anatomical position for regional block description. Reg Anesth Pain Med 2014; 39: 263-4.

16. Kishner S, Windle ML, Schraga ED. Opioid Equivalents. Medscape. Available from URL: http://emedicine.medscape.com/ article/2138678-overview (accessed March 2015).

17. di Benedetto P, Casati A, Bertini L. Continuous subgluteus sciatic nerve block after orthopedic foot and ankle surgery: comparison of two infusion techniques. Reg Anesth Pain Med 2002; 27: 168-72.
18. White PF, Issioui T, Skrivanek GD, Early JS, Wakefield C. The use of a continuous popliteal sciatic nerve block after surgery involving the foot and ankle: does it improve the quality of recovery? Anesth Analg 2003; 97: 1303-9.

19. Zaric D, Boysen K, Christiansen J, Haastrup U, Kofoed H, Rawal $N$. Continuous popliteal sciatic nerve block for outpatient foot surgery-a randomized, controlled trial. Acta Anaesthesiol Scand 2004; 48: 337-41.

20. Singelyn FJ, Aye F, Gouverneur JM. Continuous popliteal sciatic nerve block: an original technique to provide postoperative analgesia after foot surgery. Anesth Analg 1997; 84: 383-6.

21. Ilfeld BM, Morey TE, Wang RD, Enneking FK. Continuous popliteal sciatic nerve block for postoperative pain control at home: a randomized, double-blinded, placebo-controlled study. Anesthesiology 2002; 97: 959-65.

22. Chelly JE, Greger J, Casati A, Al-Samsam T, McGarvey W, Clanton T. Continuous lateral sciatic blocks for acute postoperative pain management after major ankle and foot surgery. Foot Ankle Int 2002; 23: 749-52.

23. Elliot $R$, Pearce CJ, Seifert $C$, Calder JD. Continuous infusion versus single bolus popliteal block following major ankle and hindfoot surgery: a prospective, randomized trial. Foot Ankle Int 2010; 31: 1043-7.

24. Jaeger P, Grevstad U, Henningsen MH, Gottschau B, Mathiesen $O$, Dahl JB. Effect of adductor-canal-blockade on established, severe post-operative pain after total knee arthroplasty: a randomised study. Acta Anaesthesiol Scand 2012; 56: 1013-9.

25. Grevstad U, Mathiesen O, Lind T, Dahl JB. Effect of adductor canal block on pain in patients with severe pain after total knee arthroplasty: a randomized study with individual patient analysis. Br J Anaesth 2014; 112: 912-9.

26. Perlas A, Kirkham KR, Billing $R$, et al. The impact of analgesic modality on early ambulation following total knee arthroplasty. Reg Anesth Pain Med 2013; 38: 334-9.

27. Espelund M, Fomsgaard JS, Haraszuk J, Dahl JB, Mathiesen O. The efficacy of adductor canal blockade after minor arthroscopic knee surgery - a randomised controlled trial. Acta Anaesthesiol Scand 2014; 58: 273-80.

28. Espelund M, Fomsgaard JS, Haraszuk J, Mathiesen O, Dahl JB. Analgesic efficacy of ultrasound-guided adductor canal blockade after arthroscopic anterior cruciate ligament reconstruction: a randomised controlled trial. Eur J Anaesthesiol 2013; 30: 422-8.

29. Hanson NA, Derby RE, Auyong DB, et al. Ultrasound-guided adductor canal block for arthroscopic medial meniscectomy: a randomized, double-blind trial. Can J Anesth 2013; 60: 874-80.

30. Ehlers L, Jensen JM, Bendtsen TF. Cost-effectiveness of ultrasound vs nerve stimulation guidance for continuous sciatic nerve block. Br J Anaesth 2012; 109: 804-8. 